Pharmacol Ther. 2014 July ; 143(1): 111-118. doi:10.1016/j.pharmthera.2014.02.008.

\title{
Past Strategies and Future Directions for Identifying AMP- Activated Protein Kinase (AMPK) Modulators
}

\author{
Sarah E. Sinnett ${ }^{\mathrm{a}}$ and Jay E. Brenman ${ }^{\mathrm{b}, \mathrm{c},{ }^{*}}$ \\ a Neurobiology Curriculum, University of North Carolina at Chapel Hill (UNC) \\ b UNC Neuroscience Center \\ ${ }^{c}$ Department of Cell Biology and Physiology, UNC
}

\begin{abstract}
AMP-activated protein kinase (AMPK) is a promising therapeutic target for cancer, type II diabetes, and other illnesses characterized by abnormal energy utilization. During the last decade, numerous labs have published a range of methods for identifying novel AMPK modulators. The current understanding of AMPK structure and regulation, however, has propelled a paradigm shift in which many researchers now consider ADP to be an additional regulatory nucleotide of AMPK. How can the AMPK community apply this new understanding of AMPK signaling to translational research? Recent insights into AMPK structure, regulation, and holoenzyme-sensitive signaling may provide the hindsight needed to clearly evaluate the strengths and weaknesses of past AMPK drug discovery efforts. Improving future strategies for AMPK drug discovery will require pairing the current understanding of AMPK signaling with improved experimental designs.
\end{abstract}

\section{Keywords}

AMPK; High-throughput screening; Regulatory fragment; Drug discovery; Dephosphorylation inhibition; Nucleotide analogs

\section{Introduction}

\subsection{Physiological roles of AMPK}

AMPK is an energy sensor that lies at the nexus of a complex network of anabolic and catabolic signaling pathways (Carling, Thornton, Woods, \& Sanders, 2012; Hardie, Ross, \& Hawley, 2012; Russo, Russo, \& Ungaro, 2013). With holoenzymes present in the cytoplasm and the nucleus, AMPK can mediate both rapid changes (i.e., phosphorylation of

(C) 2014 Elsevier Inc. All rights reserved

"Corresponding author. 8105 Neuroscience Research Center, 115 Mason Farm Road, Campus Box 7250, Chapel Hill, NC 27599. Tel.: 919-843-3637; fax: 919-966-9605. brenman@med.unc.edu (J. Brenman)..

Publisher's Disclaimer: This is a PDF file of an unedited manuscript that has been accepted for publication. As a service to our customers we are providing this early version of the manuscript. The manuscript will undergo copyediting, typesetting, and review of the resulting proof before it is published in its final citable form. Please note that during the production process errors may be discovered which could affect the content, and all legal disclaimers that apply to the journal pertain.

Conflict of interest statement

The authors declare that there are no conflicts of interest. 
cytoplasmic targets) and gradual adjustments (i.e., changes in gene transcription) to maintain energetic homeostasis (Fig. 1) (Hardie, 2013; Hardie, et al., 2012; Kodiha, Rassi, Brown, \& Stochaj, 2007). As a ubiquitously expressed protein complex, AMPK's regulatory reach extends well beyond the cell membrane. From head to toe, AMPK sustains the energetic demands of the brain, helps muscles adapt to strenuous workloads, and regulates hepatic energy stores in response to fasting and feasting (Carling, et al., 2012; Moore, Coate, Winnick, An, \& Cherrington, 2012; Richter \& Hargreaves, 2013). Many investigators have dissected and described AMPK signaling pathways in research papers and reviews.

Although descriptions of these pathways fall beyond the scope of this review, we encourage clinicians and investigators to revisit these publications (Carling, et al., 2012; Hardie, 2013; Hardie, et al., 2012; Russo, et al., 2013).

\subsection{AMPK structure and regulation}

AMPK is a conserved serine/threonine kinase expressed in nearly all eukaryotes (MirandaSaavedra, et al., 2007; Russo, et al., 2013). Detailed descriptions of AMPK structure and regulation can be found in reviews (Carling, et al., 2012; Hardie, et al., 2012; Russo, et al., 2013). In short, AMPK is composed of a catalytic a subunit, a scaffolding $\beta$ subunit, and a regulatory $\gamma$ subunit (Fig. 2) (Russo, et al., 2013). Mammals express multiple isoforms of each subunit $\left(a_{1}, \alpha_{2}, \beta_{1}, \beta_{2}, \gamma_{1}, \gamma_{2}\right.$, and $\left.\gamma_{3}\right)$ (Russo, et al., 2013). Phosphorylation of threonine 172 (T172) on AMPK- $\alpha$ is required for kinase activity (Carling, et al., 2012; Hardie, et al., 2012) (Fig. 2). Upon binding to AMPK- $\gamma$, AMP can promote phosphorylation of T172, allosterically increase activity of phosphorylated AMPK (p-AMPK), and protect pAMPK from dephosphorylation by protein phosphatases (Fig. 2) (Carling, et al., 2012; Hardie, et al., 2012). In addition, ADP can inhibit dephosphorylation upon binding to AMPK- $\gamma$ (Fig. 2) (Carling, et al., 2012; Hardie, et al., 2012; Xiao, et al., 2011). Finally, phosphorylation and myristoylation of AMPK- $\beta$ have been shown to regulate subcellular distribution of AMPK- $\beta$ (Fig. 2) (Sanz, Rubio, \& Garcia-Gimeno, 2013). Other possible AMPK regulatory mechanisms, such as redox sensitivity and oligomerization, have also been proposed (Cardaci, Filomeni, \& Ciriolo, 2012; Scholz, et al., 2009).

Due to the large number of diverse ligand-binding sites on AMPK, delineating AMPK regulatory mechanisms has been challenging for researchers. Altogether, AMPK has four potential adenine nucleotide-binding sites - one site on AMPK- $a$ and three sites on AMPK$\gamma$ (Carling, et al., 2012; Russo, et al., 2013). In addition, AMPK- $\gamma$ has a fourth, constitutively unoccupied site with no known function (Carling, et al., 2012; Russo, et al., 2013). Of the four nucleotide-binding sites, no two sites have identical functions or identical ligand binding affinities (Carling, et al., 2012; Gowans, Hawley, Ross, \& Hardie, 2013; Russo, et al., 2013; Xiao, et al., 2011). Furthermore, the in vitro binding affinities of these sites vary greatly depending on buffer conditions (Xiao, et al., 2007). This sensitivity to buffer conditions should be considered when comparing experimental results across publications. To illustrate the differences among these sites, AMP reversibly binds the allosteric activation site (commonly referred to as "Site 1") and the dephosphorylation inhibition site (commonly referred to as "Site 3") with strong and weak affinities, respectively (Xiao, et al., 2011). In contrast, AMP constitutively occupies the remaining binding site on AMPK- $\gamma$ (commonly referred to as "Site 4"), while supra-physiological 
concentrations of AMP must be present to occupy the active site on AMPK- $a$ - in which case, AMP would inhibit AMPK (Gowans, et al., 2013; Hardie, et al., 2012). Interestingly, point mutation studies have led some researchers to believe that Site 3 mediates allosteric activation by AMP (Chen, et al., 2012). Indeed, a crystal structure of AMPK prepared with a low concentration of AMP shows binding of AMP to Site 3, but not at Site 1 (Xiao, et al., 2011). Regardless of the conflicting data, however, researchers appear to agree that the various nucleotide-binding sites on AMPK have distinct regulatory roles and differential ligand-binding affinities.

Researchers had been studying AMPK for over two decades by the time ADP was shown to regulate AMPK (Xiao, et al., 2011). The discovery that ADP protects p-T172 from dephosphorylation was historically significant for the AMPK research community, as these phosphatase experiments initiated a community-wide conversation about the relative importance of AMP and ADP, particularly in vivo where the concentration of ADP exceeds that of AMP (Carling, et al., 2012; Gowans, et al., 2013; Oakhill, Scott, \& Kemp, 2012; Xiao, et al., 2011). Regardless of the relative importance, however, the discovery of ADP's regulatory role shifted the community's attention toward a protective regulatory mechanism characterized in 1995, yet seldom addressed in the literature for years afterward (Davies, Helps, Cohen, \& Hardie, 1995; Goransson, et al., 2007; Sanders, Grondin, Hegarty, Snowden, \& Carling, 2007; Suter, et al., 2006). Instead, researchers often turned to AMPK substrate phosphorylation assays to help identify new modulators or characterize known modulators. The AMPK modulators Compound C, A-592107 (the structural pre-cursor of A-769662), and PT1 were all identified in protein-based activity assays before or concurrent with Xiao et al.'s phosphatase experiments (Anderson, et al., 2004; Pang, et al., 2008; Zhou, et al., 2001). The absence of phosphatases biases these activity assays toward the identification of molecules that modulate the magnitude of activity and away from the identification of molecules that modulate the duration of activity. Eventually, A-769662 was shown to both allosterically activate and protect $\mathrm{p}$-AMPK from dephosphorylation (Goransson, et al., 2007; Sanders, Ali, et al., 2007). Is it possible, however, that the inherent bias of protein-based activity assays has permitted other potentially useful AMPK drugs to be misidentified as false negatives in small molecule screens?

\subsection{Therapeutic applications of AMPK modulators}

As the umbrella of AMPK regulatory mechanisms has expanded to include dephosphorylation inhibition and subcellular localization, the list of potential therapeutic applications of AMPK modulators has also grown - both in length and complexity. Historically, attention has been directed primarily toward activating AMPK to treat diabetes (Cool, et al., 2006; Hardie, 2013; Russo, et al., 2013; Winder \& Hardie, 1999; Xie, et al., 2011). For example, the AMPK activators AICAR (the prodrug of ZMP) and A-769662 have been shown to decrease blood sugar levels in mouse models of diabetes (Fig. 3) (Carling, et al., 2012; Cool, et al., 2006). As one may expect, the beneficial effects of pharmacological AMPK activation on exercise endurance, blood glucose, and body weight can be inhibited by genetic deletion of a single AMPK subunit (Fig. 3) (Carling, et al., 2012; Giri, et al., 2006; Halseth, Ensor, White, Ross, \& Gulve, 2002; Narkar, et al., 2008; Steinberg, et al., 2010). In addition, cancer biologists have shown that, under certain 
conditions, AMPK activation can inhibit tumor cell proliferation and cell growth (Hardie \& Alessi, 2013).

Researchers have also found distinct therapeutic applications for AMPK inhibition. Tumor cells, for example, may rely on activated AMPK to survive nutrient-poor, hypoxic conditions during solid tumor formation (Hardie \& Alessi, 2013; Jeon \& Hay, 2012). In addition, knockout of both AMPK- $a_{1}$ and $-a_{2}$ has been shown to decrease proliferation of astrocytes expressing the constitutively active oncogene HRas ${ }^{\mathrm{V} 12}$ (Rios, et al., 2013). Finally, inhibition of AMPK by ischemic preconditioning, Compound C (a non-selective AMPK inhibitor), and genetic deletion of AMPK- $a_{2}$ has been shown to reduce infarct volumes in mouse models of ischemia (Fig. 3) (J. Li, Zeng, Viollet, Ronnett, \& McCullough, 2007; Manwani \& McCullough, 2013; Venna, Li, Benashski, Tarabishy, \& McCullough, 2012). Clearly, there is a need for both inhibitors and activators that directly regulate AMPK. Unfortunately, the direct AMPK inhibitors Compound $\mathrm{C}$ and sunitinib are promiscuous; in contrast, direct AMPK activators may have poor bioavailability or regulate only a subset of AMPK holoenzymes (Table 1) (Chu, et al., 2007; Karagounis \& Hawley, 2009; Kerkela, et al., 2009; Laderoute, Calaoagan, Madrid, Klon, \& Ehrlich, 2010; Y. Y. Li, et al., 2013; Machrouhi, et al., 2010; Scott, et al., 2008).

\section{Strategies to identify selective AMPK modulators}

\subsection{The double-life of the first selective AMPK inhibitor}

Compound $\mathrm{C}$, one of the most commonly used AMPK inhibitors, was first identified in a high-throughput kinase assay (Table 1) (Zhou, et al., 2001). Originally described as a selective inhibitor, Compound $\mathrm{C}$ was eventually shown to inhibit many kinases. (Machrouhi, et al., 2010; Zhou, et al., 2001). Even though AMPK researchers are now well aware of Compound C's promiscuity, many may not realize that Compound $\mathrm{C}$ is also sold under the name "dorsomorphin". The name "dorsomorphin" is derived from the molecule's ability to regulate dorsalization of zebrafish embryos via inhibition of bone morphogenetic protein (BMP) receptors (P. B. Yu, et al., 2008). In agreement with this discovery, another lab published the structure of dorsomorphin binding to the ATP-binding site of a type 1 BMP receptor kinase (Chaikuad, et al., 2012). Although the first description of dorsomorphin states that the inhibitor is "structurally identical to Compound C", the term dorsomorphin and its AMPK-independent effects during development have seldom been mentioned in AMPK papers, despite the prevalent use of Compound C (P. B. Yu, et al., 2008).

\subsection{Orthogonal strategies to identify AMPK modulators}

To determine if the structure of Compound $\mathrm{C}$ could be optimized to improve selectivity for the catalytic site of AMPK- $a$, researchers simulated binding of Compound $\mathrm{C}$ fragments to human AMPK- $a_{2}$ (Machrouhi, et al., 2010). The fragment-based drug design (FBDD) strategy helped generate a collection of molecules that directly inhibited AMPK (Machrouhi, et al., 2010). However, of the molecules tested in a kinase selectivity panel, each was shown to potently inhibit one or more off-target kinases (Machrouhi, et al., 2010). Clearly, FBDD did not eliminate off-target effects. The strategy did, however, generate a collection of molecules with biased selectivity profiles and, if paired with the right 
molecular scaffold, could prove to be enormously helpful for guiding AMPK drug discovery.

To realize the full potential of FBDD, one may need to generate in silico fragments for a molecule shown to bind not at the highly conserved ATP-binding active site, but at a less conserved regulatory site on AMPK. Candidate binding sites may include regulatory Sites 1 and 3 , the recently discovered binding site for A-769662, or the predicted binding sites for the direct activators C24 or PT1 (which have not yet been crystallographically identified!) (Fig. 2, Table 1) (Y. Y. Li, et al., 2013; Pang, et al., 2008; Xiao, et al., 2013; L. F. Yu, et al., 2013). Indeed, investigators outside of the AMPK community have already successfully used FBDD to develop the anti-tumor molecule ABT-263 (a Bcl-2 family inhibitor) and the anti-coagulant LY517717 (a Factor X inhibitor) (Denas \& Pengo, 2013; Erlanson, 2012). Thus, it is possible to use FBDD to develop drugs that target different types of ligandbinding sites, including but not limited to canonical kinase active sites.

As an alternative to targeting a single binding site, an in silico or in vitro screen could be designed to target a larger regulatory region including multiple known (and perhaps unknown) ligand-binding sites. A recently developed high-throughput assay aims to detect small molecules that bind AMPK through displacement of a protein-sensitive fluorescent probe shown to bind the AMPK regulatory region (Fig. 4) (S. Sinnett, J. Sexton, \& J. Brenman, 2013). The rationale for this assay was based on insights gained from published crystal structures of mammalian AMPK (Xiao, et al., 2007; Xiao, et al., 2011). These crystal structures were a long-awaited milestone for the AMPK community, as they helped to pinpoint the ADP/AMP-binding regulatory sites on AMPK- $\gamma$ (Xiao, et al., 2007; Xiao, et al., 2011). In addition, the structures illustrated the differential ligand-binding affinities of AMPK's nucleotide-binding sites, confirmed that fluorescent coumarin- and methylanthraniloyl (MANT)-labeled nucleotides bind AMPK- $\gamma$, identified intermolecular interactions between protein residues and bound nucleotides, and illustrated the conformation of the AMPK "regulatory fragment", which is missing the kinase active site (Fig. 4) (Xiao, et al., 2007; Xiao, et al., 2011). Equipped with these new insights, researchers were then able to design a high-throughput screening assay using MANT-ADP, a proteinsensitive fluorescent probe that detects competitive binding of ADP to the regulatory fragment and full-length AMPK (Fig. 4) (S. Sinnett, et al., 2013). Investigators who use this assay to identify molecules that bind full-length AMPK can then confirm that these molecules bind the regulatory region in a secondary assay using the regulatory fragment (S. Sinnett, et al., 2013).

\subsection{Unexplored methods}

To facilitate drug discovery, the binding assay described in the previous section must be paired with orthogonal studies to determine if molecules that bind AMPK also regulate activity. Molecules that bind but have no effect on activity may be candidates for optimization through structure-activity-relationship studies (SAR). If the binding sites are identified, FBDD could potentially be used as a tool to guide molecular synthesis. Structural biologists have made strides that may pave the way for the successful application of FBDD. The AMPK community now has a wide range of published AMPK structures generated 
from protein crystals soaked with nucleotides and protein co-crystallized with nucleotides (Chen, et al., 2012; Xiao, et al., 2007; Xiao, et al., 2013; Xiao, et al., 2011). The choice of crystallization technique may be important, as the soaked AMPK structures counterintuitively demonstrate no major conformational changes upon nucleotide binding (Chen, et al., 2012). Indeed, investigators have noted conflicting data between soaked and cocrystallized structures for other proteins (e.g., the signaling molecule p38a and the antiviral protein griffithsin) (Azevedo, et al., 2012; Ziolkowska, Shenoy, O'Keefe, \& Wlodawer, 2007). Recently, a group of AMPK researchers concluded that AMPK does undergo conformational changes upon nucleotide binding based on their comparisons of cocrystallized ATP-bound regulatory fragment (rat $\alpha_{1} \beta_{1} \gamma_{1}$ ) and AMP-bound regulatory fragment (rat $\alpha_{1}$, human $\beta_{2}$, rat $\gamma_{1}$ ) (Chen, et al., 2012). By comparing both techniques against a single holoenzyme, researchers may be able to confirm this conclusion. For those investigators who choose to begin drug discovery projects with in silico FBDD, the use of accurate, physiologically representative crystal structures - be they soaked or co-crystallized - may prove to be useful for the development of successful drugs.

A recent discovery that may expedite AMPK drug discovery is the identification of the binding site for the direct activator A-769662 (Xiao, et al., 2013). Crystallographic data indicate that A-769662 binds at the interface between AMPK- $\alpha$ and $-\beta$ (Xiao, et al., 2013). In addition, researchers have proposed a mechanism explaining how A-769662 can mimic the allosteric effects of AMP without binding to AMPK- $\gamma$ (Xiao, et al., 2013). The crystal structures of A-769662 and the AMP-mimetic 991, each bound to p-AMPK, are major milestones for the AMPK community, as they are the first to pinpoint a regulatory nonnucleotide binding site in vitro (Xiao, et al., 2013). Now that the binding site for A-769662 has been identified, the AMPK community may perhaps look forward to the in vitro confirmation of the predicted binding sites for the non-nucleotide modulators C24 and PT1 (Table 1). These new insights into AMPK structure and regulation should be strongly welcomed by AMPK researchers directing drug discovery efforts. How can the identification of new ligand-binding sites accelerate translational research? In contrast to the MANT-ADP assay described previously, if researchers design an assay that targets a nonnucleotide-binding site, then this second-generation binding assay may have a greater chance of helping to identify selective AMPK modulators. Now that the binding site for A-769662 has been identified, one may be able to rationally synthesize fluorescent A-769662 analogs to help detect small molecules that bind AMPK in a mutually exclusive manner. If successful, this strategy would identify non-nucleotide-like AMPK-binding molecules that would otherwise pass as false negatives in the complementary MANT-ADP assay. Finally, the identification of non-nucleotide-like modulators may be particularly appealing to clinicians, as nucleoside analogs (e.g., AICAR) often have poor oral bioavailability (Table 1) (Karagounis \& Hawley, 2009; F. Li, Maag, \& Alfredson, 2008).

\section{Identification of holoenzyme-sensitive modulators}

\subsection{Functional differences among subunit isoforms}

Mammalian AMPK subunits can assemble into twelve distinct heterotrimers, or holoenzymes $\left(a_{1} \beta_{1} \gamma_{1}, a_{1} \beta_{1} \gamma_{2}, a_{1} \beta_{1} \gamma_{3}\right.$, etc.). Tissue-specific expression patterns of these 
holoenzymes have been published (Kim \& Tian, 2011; Quentin, et al., 2011). In short, $a_{1}$, $\beta_{1}$, and $\gamma_{1}$ subunits are moderately to highly expressed in many tissues, including lung, liver, and bone; skeletal muscle expresses high levels of $a_{2}$ and $\beta_{2}$ (Kim \& Tian, 2011). Understandably, the moderate to high expression levels of $a_{1}, \beta_{1}$, and $\gamma_{1}$ in many tissues may motivate researchers to use purified $a_{1} \beta_{1} \gamma_{1}$ in protein-based assays. Indeed, the MANT-ADP binding assay described earlier was validated and optimized in the presence of $a_{1} \beta_{1} \gamma_{1}$ (Neumann, Woods, Carling, Wallimann, \& Schlattner, 2003; S. Sinnett, et al., 2013). Likewise, other publications have used $a_{1} \beta_{1} \gamma_{1}$ for a range of in vitro studies, including crystallography, mutagenesis studies, and activity assays (Chen, et al., 2012; Neumann, et al., 2003; Sanders, Grondin, et al., 2007). The frequent use of $a_{1}$-containing complexes is particularly interesting in light of early AMPK research indicating that $a_{2^{-}}$ containing complexes from rat liver are more sensitive to allosteric activation by AMP (Salt, et al., 1998). What would happen to AMPK drug discovery efforts if researchers routinely tested a panel of AMPK heterotrimers instead of a single holoenzyme? Could small molecules differentially regulate distinct holoenzymes in drug discovery screens? Would the discovery of holoenzyme-sensitive drugs permit researchers to manipulate specific AMPK signaling pathways (e.g., cytosolic targets) while leaving other AMPK pathways (e.g., gene transcription) unperturbed, thus minimizing unwanted side effects? The answers depend on whether AMPK subunit isoforms are redundant or functionally distinct.

Inactivating mutations and genetic deletion of subunit isoforms have been shown to exert tissue-specific physiological effects. Genetic deletion of AMPK- $\beta_{2}$ and $-\gamma_{3}$, for example, has been shown to decrease exercise endurance in mice and inhibit post-exercise glycogen recovery in gastrocnemius muscle, respectively (Fig. 3) (Barnes, et al., 2004; Steinberg, et al., 2010). This result makes intuitive sense, as $\beta_{2}$-containing heterotrimers are highly expressed in skeletal muscle, and $a_{2} \beta_{2} \gamma_{3}$ has been shown to generate most of the AMPK activity in skeletal muscle during high intensity exercise (Birk \& Wojtaszewski, 2006). Similarly, mutations of highly conserved residues in AMPK- $\gamma_{2}$ have frequently been associated with human cardiomyopathies (Fig. 5) (Burwinkel, et al., 2005; Liu, et al., 2013; Moffat \& Ellen Harper, 2010). Finally, deletion of AMPK-a 2 has been shown to reduce infarct volume in mouse models of stroke, whereas deletion of $a_{1}$ does not reduce infarct volume (Kim \& Tian, 2011; J. Li, Benashski, Siegel, Liu, \& McCullough, 2010; J. Li, et al., 2007; Steinberg \& Kemp, 2009).

Aside from tissue-specific expression, how can subunits exert isoform-specific physiological effects? Subcellular localization of subunits may reduce redundancy among isoforms. For example, several in vitro techniques have consistently demonstrated differential localization of AMPK- $a_{1}$ and $-a_{2}$ in insulinoma cells (cytoplasmic versus nuclear, respectively) (Salt, et al., 1998). More recently, researchers demonstrated that leptin-stimulated expression of peroxisome proliferator-activated receptor alpha (PPAR-a) was mediated by nuclear translocation of AMPK- $a_{2}$ - but only when $a_{2}$ was bound to $\beta_{2}$ (Suzuki, et al., 2007). Since the expression of PPAR-a has been linked with activation and translocation of a specific AMPK subunit isoform, one may now begin to contemplate the therapeutic applications (such as treatment of dyslipidemia or diabetes) of a holoenzyme-specific AMPK drug (Ling, Burns, \& Hilleman, 2012). 


\subsection{Correlation between disease states and isoform expression profiles}

When characterizing AMPK under specific physiological conditions (e.g., cancer or diabetes), researchers typically measure total AMPK activity and the ratio of p-AMPK to total AMPK. Few publications comprehensively contrast the expression levels of subunit isoforms in diseased tissue versus normal control tissue (Table 2) (Kim, et al., 2012; C. Li, Liu, Chiu, Chan, \& Ngan, 2012; Merrill, et al., 2012; Sanli, Linher-Melville, Tsakiridis, \& Singh, 2012). In addition, publications typically do not contrast the percent of total AMPK activity contributed by each distinct holoenzyme in diseased tissue versus normal tissue. Would filling in this information gap help researchers identify functional differences between isoforms? If so, would AMPK researchers then be able to develop isoform-sensitive drugs that correct metabolic abnormalities in diseased tissue while leaving the metabolic pathways in healthy tissue unperturbed? This proposed strategy is similar to a genetic approach researchers recently used after observing decreased AMPK- $a_{2}$ expression in breast tumor tissue versus patient-matched non-tumor adjacent tissue (Fox, Phoenix, Kopsiaftis, \& Claffey, 2013). Genetic restoration of AMPK- $a_{2}$ in MCF7 cancer cells (which predominantly express $\mathrm{a}_{1}$ ) increased cell death in vitro and decreased tumor weight in vivo (Fox, et al., 2013).

\subsection{Therapeutic applications of holoenzyme-specific modulators}

During the past decade, AMPK researchers have identified a number of tool compounds for in vitro studies and fewer compounds suitable for animal studies (Table 1). To date, no one has intentionally designed an assay for the discovery of holoenzyme-specific AMPK modulators, but this may change as the list of potential therapeutic applications for holoenzyme-specific drugs continues to grow. This review has briefly touched upon a number of isoform-specific genetic studies whose results suggest therapeutic applications for isoform-sensitive modulators (Figs. 3, 5 and Table 2). These applications include weight management and the treatment of ischemia and cancer (Fox, et al., 2013; Giri, et al., 2006; Venna, et al., 2012). Forward-thinking researchers may ask: How does one bias drug discovery assays toward the identification of isoform-sensitive drugs?

\subsection{Past and future discoveries of isoform-sensitive modulators}

In 2004, Abbot Laboratories published a microarrayed kinase activity assay for identifying AMPK modulators (Anderson, et al., 2004). In lieu of assembling assays in wells, researchers incubated a gel containing biotinylated substrate peptide and AMPK (preincubated with compounds) between a ${ }^{33} \mathrm{P}$-ATP membrane and a streptavidin affinity membrane $\left(\mathrm{SAM}^{\mathrm{TM}}\right)$. Importantly, the AMPK used for the screen was purified from rat liver, which expresses high levels of AMPK- $\beta_{1}$ (Anderson, et al., 2004; Kim \& Tian, 2011; Stapleton, et al., 1996). After screening more than 700,000 small molecules, researchers identified 211 hits, including 3 activators (Anderson, et al., 2004). One activator, A-592107, became the structural template for A-769662 (Cool, et al., 2006). The development of A-769662 was a milestone for the AMPK community, as the drug has since been shown to selectively activate $\beta_{1}$-containing holoenzymes in vitro and in vivo at lower doses than those used for other activators (Table 1) (Cieslik, et al., 2013; Corton, Gillespie, Hawley, \& Hardie, 1995; Scott, et al., 2008). If the microarrayed screen had been performed with a $\beta_{2^{-}}$ 
containing complex, however, the structural precursor A-592107 may not have been discovered.

This drug discovery case study begs the following questions: Have other modulators been incorrectly identified as negative hits due to the choice of AMPK holoenzyme for screening? How would one identify new holoenzyme-sensitive modulators? Preparing multiple heterotrimers for parallel screening would be labor intensive. Theoretically, one could design vectors encoding distinct holoenzymes for protein expression and purification. However, both mammalian and bacterial protein expression systems have limitations. Whereas mammalian cell culture may be expensive, bacterial expression systems are unable to post-translationally modify AMPK (Oakhill, et al., 2010; Sanz, et al., 2013). In addition, researchers may worry that the conformation of AMPK purified from $E$. coli may not be physiologically representative. These limitations may push researchers toward screening small molecule libraries against AMPK holoenzymes in silico. Alternatively, a more focused starting point could be to rationally synthesize a $\beta_{2}$-sensitive modulator using existing crystallographic data. Now that the binding site for A-769662 on $\alpha_{2} \beta_{1} \gamma_{1}$ has been crystallographically identified, researchers may have an easier time identifying key structural differences between the $a-\beta$ subunit interfaces for $\beta_{1}$ - and $\beta_{2}$-containing heterotrimers. This in turn may help researchers design molecules that are tailored for the $\alpha$ $\beta_{2}$ interface.

\section{Summary}

Today's community of AMPK researchers is comprised of experts devoted to the treatment of cancer, diabetes, cardiomyopathy, and obesity. Although AMPK literature has become increasingly interdisciplinary, a recurring and unifying theme is the demand for potent, selective AMPK drugs that can either be administered to patients or be used as tool compounds for in vitro studies. Early drug discovery efforts led to the development of the AMP-mimetic A-769662 and the discovery of Compound C, an essential inhibitor found in every AMPK lab (Cool, et al., 2006; Zhou, et al., 2001). Since the first appearance of these modulators in the literature, biologists have made more strides in AMPK research. These strides include the publication of numerous AMPK structures (soaked and co-crystallized; full-length and truncated; phosphorylated and non-phosphorylated) along with the discoveries of ADP's protective role, the first non-nucleotide regulatory binding site, and the first instance of holoenzyme-sensitive pharmacological AMPK activation (Chen, et al., 2012; Scott, et al., 2008; Xiao, et al., 2013; Xiao, et al., 2011). With new insights in mind, early small molecule screens can be refined to bias drug discovery toward the identification of new molecules with diverse regulatory mechanisms.

\section{Acknowledgments}

A National Institutes of Health Grant NS080108 to J.E.B funded the authors' research. Figures were generated with the help of ChemBioDraw software. 


\section{Abbreviations}

AICAR 5-aminoimidazole-4-carboxamide 1- $\beta$-D-ribofuranoside

AMPK AMP-activated protein kinase

FBDD fragment-based drug design

MANT methylanthraniloyl

p-AMPK phosphorylated AMPK

p-T172 phosphorylated threonine 172

\section{References}

Anderson SN, Cool BL, Kifle L, Chiou W, Egan DA, Barrett LW, Richardson PL, Frevert EU, Warrior U, Kofron JL, Burns DJ. Microarrayed compound screening (microARCS) to identify activators and inhibitors of AMP-activated protein kinase. J Biomol Screen. 2004; 9:112-121. [PubMed: 15006134]

Azevedo R, van Zeeland M, Raaijmakers H, Kazemier B, de Vlieg J, Oubrie A. X-ray structure of p38alpha bound to TAK-715: comparison with three classic inhibitors. Acta Crystallogr D Biol Crystallogr. 2012; 68:1041-1050. [PubMed: 22868770]

Barnes BR, Marklund S, Steiler TL, Walter M, Hjalm G, Amarger V, Mahlapuu M, Leng Y, Johansson C, Galuska D, Lindgren K, Abrink M, Stapleton D, Zierath JR, Andersson L. The 5'AMP-activated protein kinase gamma3 isoform has a key role in carbohydrate and lipid metabolism in glycolytic skeletal muscle. J Biol Chem. 2004; 279:38441-38447. [PubMed: 15247217]

Birk JB, Wojtaszewski JF. Predominant alpha2/beta2/gamma3 AMPK activation during exercise in human skeletal muscle. J Physiol. 2006; 577:1021-1032. [PubMed: 17038425]

Burwinkel B, Scott JW, Buhrer C, van Landeghem FK, Cox GF, Wilson CJ, Grahame Hardie D, Kilimann MW. Fatal congenital heart glycogenosis caused by a recurrent activating R531Q mutation in the gamma 2-subunit of AMP-activated protein kinase (PRKAG2), not by phosphorylase kinase deficiency. Am J Hum Genet. 2005; 76:1034-1049. [PubMed: 15877279]

Cardaci S, Filomeni G, Ciriolo MR. Redox implications of AMPK-mediated signal transduction beyond energetic clues. J Cell Sci. 2012; 125:2115-2125. [PubMed: 22619229]

Carling D, Thornton C, Woods A, Sanders MJ. AMP-activated protein kinase: new regulation, new roles? Biochem J. 2012; 445:11-27. [PubMed: 22702974]

Chaikuad A, Alfano I, Kerr G, Sanvitale CE, Boergermann JH, Triffitt JT, von Delft F, Knapp S, Knaus P, Bullock AN. Structure of the bone morphogenetic protein receptor ALK2 and implications for fibrodysplasia ossificans progressiva. J Biol Chem. 2012; 287:36990-36998. [PubMed: 22977237]

Chen L, Wang J, Zhang YY, Yan SF, Neumann D, Schlattner U, Wang ZX, Wu JW. AMP-activated protein kinase undergoes nucleotide-dependent conformational changes. Nat Struct Mol Biol. 2012; 19:716-718. [PubMed: 22659875]

Cheng JQ, Jiang W, Hackney DD. Interaction of mant-adenosine nucleotides and magnesium with kinesin. Biochemistry. 1998; 37:5288-5295. [PubMed: 9548760]

Chu TF, Rupnick MA, Kerkela R, Dallabrida SM, Zurakowski D, Nguyen L, Woulfe K, Pravda E, Cassiola F, Desai J, George S, Morgan JA, Harris DM, Ismail NS, Chen JH, Schoen FJ, Van den Abbeele AD, Demetri GD, Force T, Chen MH. Cardiotoxicity associated with tyrosine kinase inhibitor sunitinib. Lancet. 2007; 370:2011-2019. [PubMed: 18083403]

Cieslik KA, Taffet GE, Crawford JR, Trial J, Mejia Osuna P, Entman ML. AICAR-dependent AMPK activation improves scar formation in the aged heart in a murine model of reperfused myocardial infarction. J Mol Cell Cardiol. 2013; 63:26-36. [PubMed: 23871790]

Cool B, Zinker B, Chiou W, Kifle L, Cao N, Perham M, Dickinson R, Adler A, Gagne G, Iyengar R, Zhao G, Marsh K, Kym P, Jung P, Camp HS, Frevert E. Identification and characterization of a 
small molecule AMPK activator that treats key components of type 2 diabetes and the metabolic syndrome. Cell Metab. 2006; 3:403-416. [PubMed: 16753576]

Corton JM, Gillespie JG, Hawley SA, Hardie DG. 5-aminoimidazole-4-carboxamide ribonucleoside. A specific method for activating AMP-activated protein kinase in intact cells? Eur J Biochem. 1995; 229:558-565. [PubMed: 7744080]

Davies SP, Helps NR, Cohen PT, Hardie DG. 5'-AMP inhibits dephosphorylation, as well as promoting phosphorylation, of the AMP-activated protein kinase. Studies using bacterially expressed human protein phosphatase-2C alpha and native bovine protein phosphatase-2AC. FEBS Lett. 1995; 377:421-425. [PubMed: 8549768]

Denas G, Pengo V. Investigational anticoagulants for hematological conditions: a new generation of therapies. Expert Opin Investig Drugs. 2013; 22:1281-1294.

Erlanson DA. Introduction to fragment-based drug discovery. Top Curr Chem. 2012; 317:1-32. [PubMed: 21695633]

Fox MM, Phoenix KN, Kopsiaftis SG, Claffey KP. AMP-Activated Protein Kinase alpha 2 Isoform Suppression in Primary Breast Cancer Alters AMPK Growth Control and Apoptotic Signaling. Genes Cancer. 2013; 4:3-14. [PubMed: 23946867]

Giri S, Rattan R, Haq E, Khan M, Yasmin R, Won JS, Key L, Singh AK, Singh I. AICAR inhibits adipocyte differentiation in 3T3L1 and restores metabolic alterations in diet-induced obesity mice model. Nutr Metab (Lond). 2006; 3:31. [PubMed: 16901342]

Goransson O, McBride A, Hawley SA, Ross FA, Shpiro N, Foretz M, Viollet B, Hardie DG, Sakamoto K. Mechanism of action of A-769662, a valuable tool for activation of AMP-activated protein kinase. J Biol Chem. 2007; 282:32549-32560. [PubMed: 17855357]

Gowans GJ, Hawley SA, Ross FA, Hardie DG. AMP Is a True Physiological Regulator of AMPActivated Protein Kinase by Both Allosteric Activation and Enhancing Net Phosphorylation. Cell Metab. 2013; 18:556-566. [PubMed: 24093679]

Halseth AE, Ensor NJ, White TA, Ross SA, Gulve EA. Acute and chronic treatment of ob/ob and $\mathrm{db} / \mathrm{db}$ mice with AICAR decreases blood glucose concentrations. Biochem Biophys Res Commun. 2002; 294:798-805. [PubMed: 12061777]

Hardie DG. AMPK: a target for drugs and natural products with effects on both diabetes and cancer. Diabetes. 2013; 62:2164-2172. [PubMed: 23801715]

Hardie DG, Alessi DR. LKB1 and AMPK and the cancer-metabolism link- ten years after. BMC Biol. 2013; 11:36. [PubMed: 23587167]

Hardie DG, Ross FA, Hawley SA. AMP-activated protein kinase: a target for drugs both ancient and modern. Chem Biol. 2012; 19:1222-1236. [PubMed: 23102217]

Jeon SM, Hay N. The dark face of AMPK as an essential tumor promoter. Cell Logist. 2012; 2:197202. [PubMed: 23676995]

Karagounis LG, Hawley JA. The 5' adenosine monophosphate-activated protein kinase: regulating the ebb and flow of cellular energetics. Int J Biochem Cell Biol. 2009; 41:2360-2363. [PubMed: 19628050]

Kerkela R, Woulfe KC, Durand JB, Vagnozzi R, Kramer D, Chu TF, Beahm C, Chen MH, Force T. Sunitinib-induced cardiotoxicity is mediated by off-target inhibition of AMP-activated protein kinase. Clin Transl Sci. 2009; 2:15-25. [PubMed: 20376335]

Kim M, Shen M, Ngoy S, Karamanlidis G, Liao R, Tian R. AMPK isoform expression in the normal and failing hearts. J Mol Cell Cardiol. 2012; 52:1066-1073. [PubMed: 22314372]

Kim M, Tian R. Targeting AMPK for cardiac protection: opportunities and challenges. J Mol Cell Cardiol. 2011; 51:548-553. [PubMed: 21147121]

Kodiha M, Rassi JG, Brown CM, Stochaj U. Localization of AMP kinase is regulated by stress, cell density, and signaling through the MEK-->ERK1/2 pathway. Am J Physiol Cell Physiol. 2007; 293:C1427-1436. [PubMed: 17728396]

Laderoute KR, Calaoagan JM, Madrid PB, Klon AE, Ehrlich PJ. SU11248 (sunitinib) directly inhibits the activity of mammalian 5'-AMP-activated protein kinase (AMPK). Cancer Biol Ther. 2010; 10:68-76. [PubMed: 20495370]

Lee JM, Seo WY, Song KH, Chanda D, Kim YD, Kim DK, Lee MW, Ryu D, Kim YH, Noh JR, Lee $\mathrm{CH}$, Chiang JY, Koo SH, Choi HS. AMPK-dependent repression of hepatic gluconeogenesis via 
disruption of CREB.CRTC2 complex by orphan nuclear receptor small heterodimer partner. J Biol Chem. 2010; 285:32182-32191. [PubMed: 20688914]

Li C, Liu VW, Chiu PM, Chan DW, Ngan HY. Over-expressions of AMPK subunits in ovarian carcinomas with significant clinical implications. BMC Cancer. 2012; 12:357. [PubMed: 22897928]

Li F, Maag H, Alfredson T. Prodrugs of nucleoside analogues for improved oral absorption and tissue targeting. J Pharm Sci. 2008; 97:1109-1134. [PubMed: 17696166]

Li J, Benashski SE, Siegel C, Liu F, McCullough LD. Adenosine monophosphate activated protein kinase inhibition is protective in both sexes after experimental stroke. Neurosci Lett. 2010; 482:62-65. [PubMed: 20621158]

Li J, Zeng Z, Viollet B, Ronnett GV, McCullough LD. Neuroprotective effects of adenosine monophosphate-activated protein kinase inhibition and gene deletion in stroke. Stroke. 2007; 38:2992-2999. [PubMed: 17901380]

Li YY, Yu LF, Zhang LN, Qiu BY, Su MB, Wu F, Chen DK, Pang T, Gu M, Zhang W, Ma WP, Jiang HW, Li JY, Nan FJ, Li J. Novel small-molecule AMPK activator orally exerts beneficial effects on diabetic db/db mice. Toxicol Appl Pharmacol. 2013; 273:325-334. [PubMed: 24055643]

Ling H, Burns TL, Hilleman DE. Novel strategies for managing dyslipidemia: treatment beyond statins. Postgrad Med. 2012; 124:43-54. [PubMed: 23322138]

Liu Y, Bai R, Wang L, Zhang C, Zhao R, Wan D, Chen X, Caceres G, Barr D, Barajas-Martinez H, Antzelevitch C, Hu D. Identification of a novel de novo mutation associated with PRKAG2 cardiac syndrome and early onset of heart failure. PLoS One. 2013; 8:e64603. [PubMed: 23741347]

Machrouhi F, Ouhamou N, Laderoute K, Calaoagan J, Bukhtiyarova M, Ehrlich PJ, Klon AE. The rational design of a novel potent analogue of the 5'-AMP-activated protein kinase inhibitor compound C with improved selectivity and cellular activity. Bioorg Med Chem Lett. 2010; 20:6394-6399. [PubMed: 20932747]

Manwani B, McCullough LD. Function of the master energy regulator adenosine monophosphateactivated protein kinase in stroke. J Neurosci Res. 2013; 91:1018-1029. [PubMed: 23463465]

Merrill JF, Thomson DM, Hardman SE, Hepworth SD, Willie S, Hancock CR. Iron deficiency causes a shift in AMP-activated protein kinase (AMPK) subunit composition in rat skeletal muscle. Nutr Metab (Lond). 2012; 9:104. [PubMed: 23171474]

Miranda-Saavedra D, Stark MJ, Packer JC, Vivares CP, Doerig C, Barton GJ. The complement of protein kinases of the microsporidium Encephalitozoon cuniculi in relation to those of Saccharomyces cerevisiae and Schizosaccharomyces pombe. BMC Genomics. 2007; 8:309. [PubMed: 17784954]

Moffat C, Ellen Harper M. Metabolic functions of AMPK: aspects of structure and of natural mutations in the regulatory gamma subunits. IUBMB Life. 2010; 62:739-745. [PubMed: 21031502]

Moore MC, Coate KC, Winnick JJ, An Z, Cherrington AD. Regulation of hepatic glucose uptake and storage in vivo. Adv Nutr. 2012; 3:286-294. [PubMed: 22585902]

Narkar VA, Downes M, Yu RT, Embler E, Wang YX, Banayo E, Mihaylova MM, Nelson MC, Zou Y, Juguilon H, Kang H, Shaw RJ, Evans RM. AMPK and PPARdelta agonists are exercise mimetics. Cell. 2008; 134:405-415. [PubMed: 18674809]

Neumann D, Woods A, Carling D, Wallimann T, Schlattner U. Mammalian AMP-activated protein kinase: functional, heterotrimeric complexes by co-expression of subunits in Escherichia coli. Protein Expr Purif. 2003; 30:230-237. [PubMed: 12880772]

Oakhill JS, Chen ZP, Scott JW, Steel R, Castelli LA, Ling N, Macaulay SL, Kemp BE. beta-Subunit myristoylation is the gatekeeper for initiating metabolic stress sensing by AMP-activated protein kinase (AMPK). Proc Natl Acad Sci U S A. 2010; 107:19237-19241. [PubMed: 20974912]

Oakhill JS, Scott JW, Kemp BE. AMPK functions as an adenylate charge-regulated protein kinase. Trends Endocrinol Metab. 2012; 23:125-132. [PubMed: 22284532]

Pang T, Zhang ZS, Gu M, Qiu BY, Yu LF, Cao PR, Shao W, Su MB, Li JY, Nan FJ, Li J. Small molecule antagonizes autoinhibition and activates AMP-activated protein kinase in cells. J Biol Chem. 2008; 283:16051-16060. [PubMed: 18321858] 
Quentin T, Kitz J, Steinmetz M, Poppe A, Bar K, Kratzner R. Different expression of the catalytic alpha subunits of the AMP activated protein kinase--an immunohistochemical study in human tissue. Histol Histopathol. 2011; 26:589-596. [PubMed: 21432774]

Richter EA, Hargreaves M. Exercise, GLUT4, and skeletal muscle glucose uptake. Physiol Rev. 2013; 93:993-1017. [PubMed: 23899560]

Rios M, Foretz M, Viollet B, Prieto A, Fraga M, Costoya JA, Senaris R. AMPK activation by oncogenesis is required to maintain cancer cell proliferation in astrocytic tumors. Cancer Res. 2013; 73:2628-2638. [PubMed: 23370326]

Russo GL, Russo M, Ungaro P. AMP-activated protein kinase: a target for old drugs against diabetes and cancer. Biochem Pharmacol. 2013; 86:339-350. [PubMed: 23747347]

Salt I, Celler JW, Hawley SA, Prescott A, Woods A, Carling D, Hardie DG. AMP-activated protein kinase: greater AMP dependence, and preferential nuclear localization, of complexes containing the alpha2 isoform. Biochem J. 1998; 334(Pt 1):177-187. [PubMed: 9693118]

Sanders MJ, Ali ZS, Hegarty BD, Heath R, Snowden MA, Carling D. Defining the mechanism of activation of AMP-activated protein kinase by the small molecule A-769662, a member of the thienopyridone family. J Biol Chem. 2007; 282:32539-32548. [PubMed: 17728241]

Sanders MJ, Grondin PO, Hegarty BD, Snowden MA, Carling D. Investigating the mechanism for AMP activation of the AMP-activated protein kinase cascade. Biochem J. 2007; 403:139-148. [PubMed: 17147517]

Sanli T, Linher-Melville K, Tsakiridis T, Singh G. Sestrin2 modulates AMPK subunit expression and its response to ionizing radiation in breast cancer cells. PLoS One. 2012; 7:e32035. [PubMed: 22363791]

Sanz P, Rubio T, Garcia-Gimeno MA. AMPKbeta subunits: more than just a scaffold in the formation of AMPK complex. FEBS J. 2013; 280:3723-3733. [PubMed: 23721051]

Scholz R, Suter M, Weimann T, Polge C, Konarev PV, Thali RF, Tuerk RD, Viollet B, Wallimann T, Schlattner U, Neumann D. Homo-oligomerization and activation of AMP-activated protein kinase are mediated by the kinase domain alphaG-helix. J Biol Chem. 2009; 284:27425-27437. [PubMed: 19651772]

Scott JW, van Denderen BJ, Jorgensen SB, Honeyman JE, Steinberg GR, Oakhill JS, Iseli TJ, Koay A, Gooley PR, Stapleton D, Kemp BE. Thienopyridone drugs are selective activators of AMPactivated protein kinase beta1-containing complexes. Chem Biol. 2008; 15:1220-1230. [PubMed: 19022182]

Sinnett S, Sexton J, Brenman J. A High Throughput Assay for Discovery of Small Molecules that Bind AMP-activated Protein Kinase (AMPK). Curr Chem Genomics and Translational Medicine. 2013; 7:30-38.

Sinnett SE, Sexton JZ, Brenman JE. A High Throughput Assay for Discovery of Small Molecules that Bind AMP-activated Protein Kinase (AMPK). Curr Chem Genomics Transl Med. 2013; 7:30-38. [PubMed: 24396733]

Stapleton D, Mitchelhill KI, Gao G, Widmer J, Michell BJ, Teh T, House CM, Fernandez CS, Cox T, Witters LA, Kemp BE. Mammalian AMP-activated protein kinase subfamily. J Biol Chem. 1996; 271:611-614. [PubMed: 8557660]

Steinberg GR, Kemp BE. AMPK in Health and Disease. Physiol Rev. 2009; 89:1025-1078. [PubMed: 19584320]

Steinberg GR, O’Neill HM, Dzamko NL, Galic S, Naim T, Koopman R, Jorgensen SB, Honeyman J, Hewitt K, Chen ZP, Schertzer JD, Scott JW, Koentgen F, Lynch GS, Watt MJ, van Denderen BJ, Campbell DJ, Kemp BE. Whole body deletion of AMP-activated protein kinase \{beta\}2 reduces muscle AMPK activity and exercise capacity. J Biol Chem. 2010; 285:37198-37209. [PubMed: 20855892]

Suter M, Riek U, Tuerk R, Schlattner U, Wallimann T, Neumann D. Dissecting the role of 5'-AMP for allosteric stimulation, activation, and deactivation of AMP-activated protein kinase. J Biol Chem. 2006; 281:32207-32216. [PubMed: 16943194]

Suzuki A, Okamoto S, Lee S, Saito K, Shiuchi T, Minokoshi Y. Leptin stimulates fatty acid oxidation and peroxisome proliferator-activated receptor alpha gene expression in mouse $\mathrm{C} 2 \mathrm{C} 12$ myoblasts 
by changing the subcellular localization of the alpha2 form of AMP-activated protein kinase. Mol Cell Biol. 2007; 27:4317-4327. [PubMed: 17420279]

Venna VR, Li J, Benashski SE, Tarabishy S, McCullough LD. Preconditioning induces sustained neuroprotection by downregulation of adenosine 5'-monophosphate-activated protein kinase. Neuroscience. 2012; 201:280-287. [PubMed: 22120436]

Winder WW, Hardie DG. AMP-activated protein kinase, a metabolic master switch: possible roles in type 2 diabetes. Am J Physiol. 1999; 277:E1-10. [PubMed: 10409121]

Xiao B, Heath R, Saiu P, Leiper FC, Leone P, Jing C, Walker PA, Haire L, Eccleston JF, Davis CT, Martin SR, Carling D, Gamblin SJ. Structural basis for AMP binding to mammalian AMPactivated protein kinase. Nature. 2007; 449:496-500. [PubMed: 17851531]

Xiao B, Sanders MJ, Carmena D, Bright NJ, Haire LF, Underwood E, Patel BR, Heath RB, Walker PA, Hallen S, Giordanetto F, Martin SR, Carling D, Gamblin SJ. Structural basis of AMPK regulation by small molecule activators. Nat Commun. 2013; 4:3017. [PubMed: 24352254]

Xiao B, Sanders MJ, Underwood E, Heath R, Mayer FV, Carmena D, Jing C, Walker PA, Eccleston JF, Haire LF, Saiu P, Howell SA, Aasland R, Martin SR, Carling D, Gamblin SJ. Structure of mammalian AMPK and its regulation by ADP. Nature. 2011; 472:230-233. [PubMed: 21399626]

Xie Z, Lau K, Eby B, Lozano P, He C, Pennington B, Li H, Rathi S, Dong Y, Tian R, Kem D, Zou $\mathrm{MH}$. Improvement of cardiac functions by chronic metformin treatment is associated with enhanced cardiac autophagy in diabetic OVE26 mice. Diabetes. 2011; 60:1770-1778. [PubMed: 21562078]

Yoon YS, Lee MW, Ryu D, Kim JH, Ma H, Seo WY, Kim YN, Kim SS, Lee CH, Hunter T, Choi CS, Montminy MR, Koo SH. Suppressor of MEK null (SMEK)/protein phosphatase 4 catalytic subunit (PP4C) is a key regulator of hepatic gluconeogenesis. Proc Natl Acad Sci U S A. 2010; 107:17704-17709. [PubMed: 20876121]

Yu LF, Li YY, Su MB, Zhang M, Zhang W, Zhang LN, Pang T, Zhang RT, Liu B, Li JY, Li J, Nan FJ. Development of Novel Alkene Oxindole Derivatives As Orally Efficacious AMP-Activated Protein Kinase Activators. Acs Medicinal Chemistry Letters. 2013; 4:475-480.

Yu PB, Hong CC, Sachidanandan C, Babitt JL, Deng DY, Hoyng SA, Lin HY, Bloch KD, Peterson RT. Dorsomorphin inhibits BMP signals required for embryogenesis and iron metabolism. Nat Chem Biol. 2008; 4:33-41. [PubMed: 18026094]

Zhou G, Myers R, Li Y, Chen Y, Shen X, Fenyk-Melody J, Wu M, Ventre J, Doebber T, Fujii N, Musi N, Hirshman MF, Goodyear LJ, Moller DE. Role of AMP-activated protein kinase in mechanism of metformin action. J Clin Invest. 2001; 108:1167-1174. [PubMed: 11602624]

Ziolkowska NE, Shenoy SR, O'Keefe BR, Wlodawer A. Crystallographic studies of the complexes of antiviral protein griffithsin with glucose and N-acetylglucosamine. Protein Sci. 2007; 16:14851489. [PubMed: 17567736] 


\section{A. Regulation of ACC signaling}

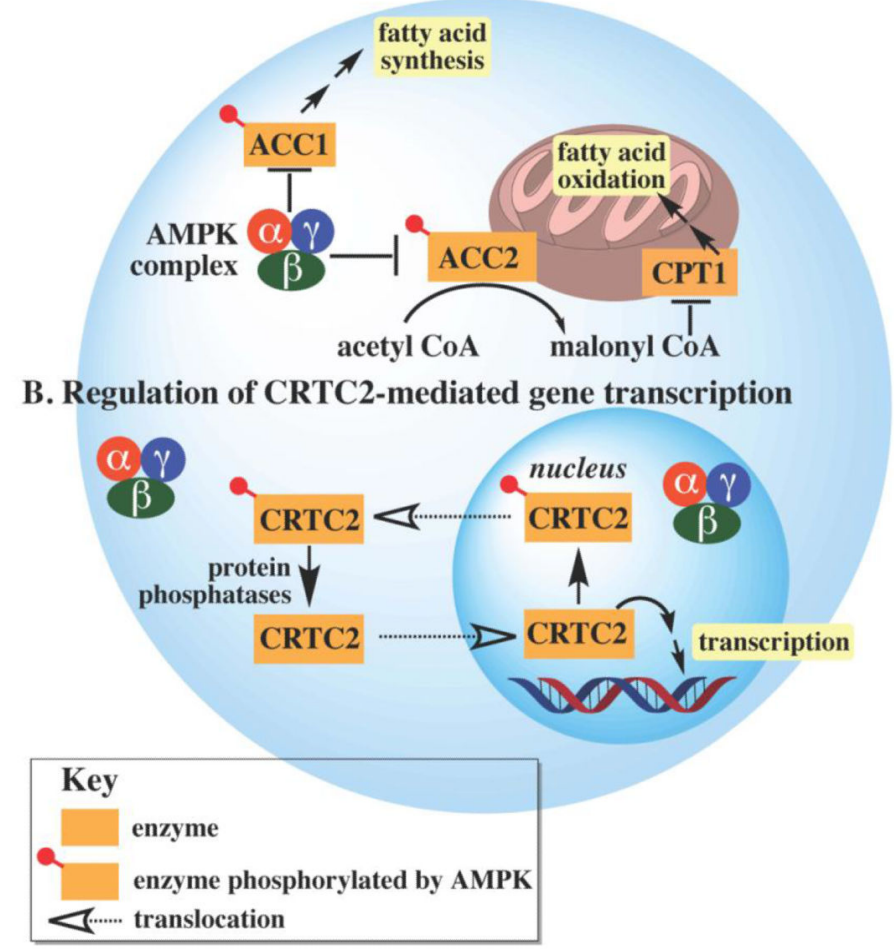

Fig. 1.

A partial list of AMPK targets. A. AMPK phosphorylates and inhibits acetyl CoA carboxylase 1 and 2 (ACC1 and ACC2), resulting in decreased fatty acid synthesis and increased fatty acid oxidation, respectively (Hardie, et al., 2012). CPT1, carnitine palmitoyltransferase 1. B. AMPK phosphorylates CREB-regulated transcription coactivator 2 (CRTC2). Phosphorylation sequesters the coactivator to the cytoplasm, ultimately downregulating gluconeogenesis (Hardie, et al., 2012; Yoon, et al., 2010). The graphical portrayal of this pathway varies, with some authors depicting phosphorylation of CRTC 2 by AMPK prior to nuclear export; others depict only cytoplasmic phosphorylation (Lee, et al., 2010; Steinberg \& Kemp, 2009). 


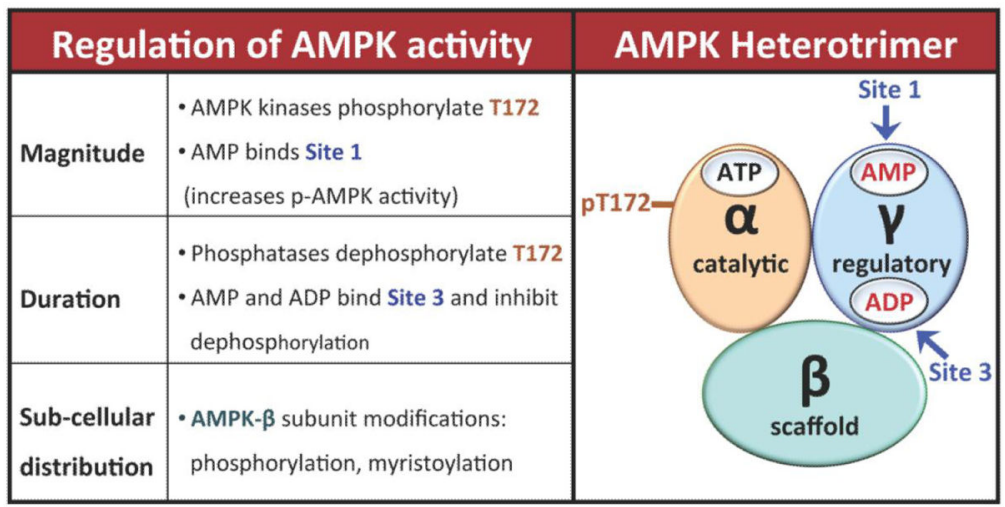

Fig. 2.

Regulatory mechanisms of AMPK. The simplified cartoon shows two nucleotide-binding sites on AMPK- $\gamma$. The remaining sites (Site 2 and Site 4) are omitted for clarity (Carling, et al., 2012; Hardie, et al., 2012; Russo, et al., 2013; Sanz, et al., 2013). 
A. Pharmacological activation of AMPK

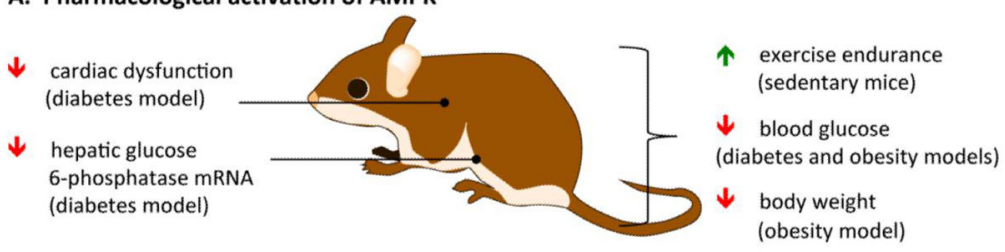

B. Genetic deletion of AMPK subunits

$\downarrow$ Infarct volume after stroke (AMPK- $\alpha_{2}$ )

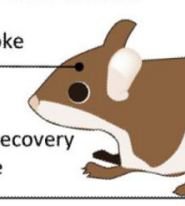

in gastrocnemius muscle (AMPK- $\gamma_{3}$ )

$\downarrow$ exercise endurance (AMPK- $\beta_{2}$ )

$\uparrow$ blood glucose $\left(\right.$ AMPK- $\beta_{2}$ )

$\uparrow$ body weight $\left(\mathrm{AMPK}-\beta_{2}\right)$

Fig. 3.

In vivo studies. A. The effects of pharmacological activation of AMPK have been studied in models of diabetes, obesity, and sedentary lifestyle (Carling, et al., 2012; Cool, et al., 2006; Giri, et al., 2006; Halseth, et al., 2002; Narkar, et al., 2008; Xie, et al., 2011). B. Genetic deletion of isoforms has been studied in models of energetic stress. Deleted isoforms are indicated in parentheses (Barnes, et al., 2004; Steinberg, et al., 2010; Venna, et al., 2012). 

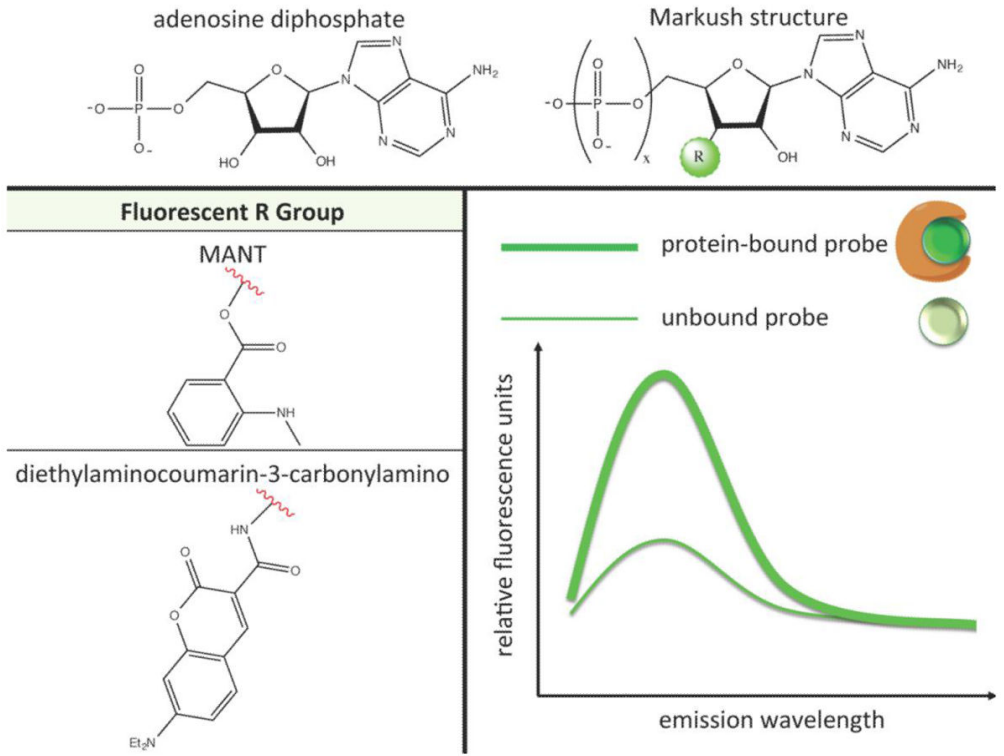

Fig. 4.

Protein-sensitive fluorescent probes. MANT- and coumarin-labeled nucleotides have been used to detect binding of molecules to the AMPK regulatory region (S. E. Sinnett, J. Z. Sexton, \& J. E. Brenman, 2013; Xiao, et al., 2007; Xiao, et al., 2011). The Markush structure depicts the structure of adenine nucleotides that can be labeled with MANT and coumarin moieties. Note that the MANT moiety can substitute the $2^{\prime}$ or $3^{\prime}$ ribosyl hydroxyl (Cheng, Jiang, \& Hackney, 1998). The stylized inset graph shows the protein-sensitive signal of a hypothetical probe. 


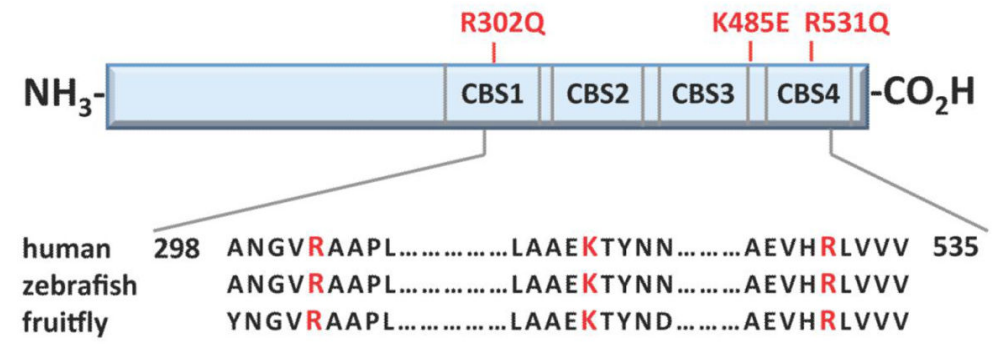

\begin{tabular}{|c|c|}
\hline $\begin{array}{l}\text { AMPK- } \gamma_{2} \\
\text { mutation }\end{array}$ & Effect on AMPK \\
\hline R302Q & $\uparrow$ activity relative to total protein; $\downarrow$ activity relative to heart weight \\
\hline K485E & $\downarrow$ interaction between AMPK- $\gamma_{2}$ and $-\beta$ in silico \\
\hline R531Q & $\downarrow$ allosteric activation in vitro \\
\hline
\end{tabular}

Fig. 5.

A partial list of AMPK- $\gamma_{2}$ mutations observed in patients with cardiomyopathy (Burwinkel, et al., 2005; Liu, et al., 2013; Moffat \& Ellen Harper, 2010). These mutations affect residues (red) that are highly conserved throughout Eukarya. CBS, cystathionine- $\beta$-synthase domains in AMPK- $\gamma$. 


\section{Table 1}

Direct modulators of AMPK.

\begin{tabular}{|c|c|c|c|c|c|}
\hline \multirow[t]{2}{*}{ Molecule } & \multirow[t]{2}{*}{ Effect } & \multirow[t]{2}{*}{ Binding site } & \multicolumn{2}{|c|}{ Commonly used concentrations } & \multirow[t]{2}{*}{ Limitations } \\
\hline & & & In vitro $(\mu \mathrm{M})$ & Rodents (mg/kg) ${ }^{\#}$ & \\
\hline A-769662 1 & $\uparrow$ activity, protection & $\begin{array}{l}\text { Between AMPK- } a \text { and } \\
-\beta\end{array}$ & $*_{1}-10 ; \S_{10-300}$ & $3-30$ & targets $\beta_{1}$-complexes \\
\hline $\mathrm{C}_{2} 4^{2}$ & $\uparrow$ activity & AMPK-a (in silico) & $*_{1} 1-20 ; \S_{5}-20$ & 50-150 (oral gavage) & ND \\
\hline Compound $\mathrm{C}^{3}$ & $\downarrow$ activity & AMPK-a & $*_{<1 ;} \S_{10-40}$ & $10-20$ & promiscuous \\
\hline PT1 ${ }^{4}$ & $\uparrow$ activity & AMPK-a & $*_{<}<10 ; \S_{10-80}$ & No published experiments & poor oral availability \\
\hline $\mathrm{ZMP}^{5}$ & $\uparrow$ activity & AMPK- $\gamma$ & $\begin{array}{l}* 150-1500(\mathrm{ZMP}) \\
\S_{300}-1000(\text { AICAR })\end{array}$ & 500 (AICAR) & $\begin{array}{l}\text { short half-life, poor } \\
\text { bioavailability }\end{array}$ \\
\hline sunitinib $^{6}$ & $\downarrow$ activity & AMPK-a (in silico) & $*_{<1} ; \S_{5}-20$ & $10-25 \mathrm{mg} / \mathrm{kg}$ (with food) & promiscuous, toxic \\
\hline $\mathrm{C}_{-\mathrm{OH}}^{\mathrm{N}}$ & $\mathrm{C24}$ & Compound C & PT1 & ZMP & sunitinib \\
\hline
\end{tabular}

cell-free assays

$\S_{\text {cell-intact assays }}$

${ }^{\#}$ drugs delivered intraperitoneally, except where otherwise noted. ND, not determined.

${ }^{1}$ (Cool, et al., 2006; Goransson, et al., 2007; Sanders, Ali, et al., 2007; Scott, et al., 2008; Xiao, et al., 2013)

${ }^{2}$ (Y. Y. Li, et al., 2013; L. F. Yu, et al., 2013)

3 (J. Li, et al., 2007; Machrouhi, et al., 2010; Venna, et al., 2012; Zhou, et al., 2001)

${ }^{4}$ (Y. Y. Li, et al., 2013; Pang, et al., 2008)

5 (Cieslik, et al., 2013; Cool, et al., 2006; Corton, et al., 1995; Karagounis \& Hawley, 2009)

${ }^{6}$ (Chu, et al., 2007; Kerkela, et al., 2009; Laderoute, et al., 2010). 
Table 2

Correlation between physiological conditions and isoform expression profiles. Except where otherwise noted, expression levels are compared to those of healthy controls.

\begin{tabular}{|l|l|c|c|c|c|}
\hline Illness/stressor & \multirow{2}{*}{ Tissue source } & \multicolumn{4}{|c|}{ Protein expression } \\
\cline { 3 - 7 } & & $\alpha_{1}$ & $\alpha_{2}$ & $\beta_{1}$ & $\beta_{2}$ \\
\hline iron deficiency $^{1}$ & rat skeletal muscle & $\uparrow$ & $\downarrow$ & - & $\downarrow$ \\
\hline heart failure $^{2}$ & mouse heart & -- & $\uparrow$ & $\downarrow$ & $\uparrow$ \\
\hline heart failure $^{2}$ & human heart & $\uparrow$ & -- & $\uparrow$ & -- \\
\hline ovarian cancer $^{3}$ & human ovaries & -- & $\uparrow$ & $\uparrow$ & $\uparrow$ \\
\hline $\begin{array}{l}\text { breast cancer with elevated expression of } \\
\text { the metabolic regulator sestrin }\end{array}$ & MCF7 cells & $\uparrow$ & none & $\uparrow$ & ND \\
\hline
\end{tabular}

* Expression levels compared to those of low sestrin breast cancer control.

\# Protein not detected in cell line. ND, no recorded data

no change.

${ }^{1}$ (Merrill, et al., 2012)

${ }^{2}$ (Kim, et al., 2012)

3 (C. Li, et al., 2012)

${ }^{4}$ (Sanli, et al., 2012). 